\title{
Influence of Coking Pressure and Oven Age on Chamber Wall Displacement and Coke Pushing Force
}

\author{
Tomoyuki NAKAGAWA, ${ }^{11}$ Yukihiro KUBOTA, ${ }^{11}$ Takashi ARIMA, ${ }^{1)}$ Koichi FUKUDA, ${ }^{1)}$ Kenji KATO,

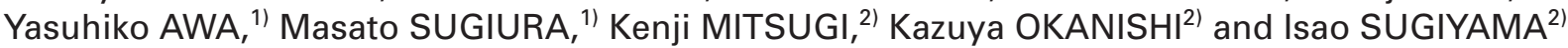

1) Nippon Steel Corporation, Environment and Process Development Center, 20-1 Shintomi, Futtsu, Chiba $293-8511$ Japan.

2) Hokkai Iron \& Coke Company, 12 Nakamachi, Muroran, Hokkaido 050-0087 Japan.

(Received on August 30, 2010; accepted on November 4, 2010)

\begin{abstract}
Relationship between coking pressure and displacement of oven wall during carbonization in coke oven was investigated at Hokkai No. 6 coke oven battery (preheated-coal charging system). Determination was performed at both a superannuated oven chamber after 26 years from start and a sturdy oven chamber after a year from replacement of oven top, entire walls and oven sole. Wall displacement was observed when the internal gas pressure of plastic layer at oven center became the maximum in both oven chambers. The wall displacement increased in proportion to the internal gas pressure of plastic layer at oven center, and the displacement at superannuated oven per maximum gas pressure was larger than the one at sturdy oven. The pushing force (maximum electric current of pushing machine) greatly changed according to gas pressure of plastic layer at superannuated oven compared with the one at sturdy oven. The conclusion of this study is that the wall displacement by coking pressure greatly influences the pushing force of coke cake at superannuated oven chamber.
\end{abstract}

KEY WORDS: carbonization; coking pressure; wall displacement; coke oven.

\section{Introduction}

When coal is carbonized in a coke oven chamber to produce coke, the gas in the plastic zone of the coal exerts pressure (coking pressure) on chamber walls, ${ }^{1-3)}$ which varies depending on factors, such as the brand and the bulk density of the coal in the chamber. When the pressure is high, chamber walls may suffer heavy damage, ${ }^{1-3)}$ and the resistance to the pushing operation for discharging coke may increase. ${ }^{4,5)}$ With respect to the latter, while a gap forms between the coke cake and the chamber wall because of the lateral shrinkage of coal during coking, the gap is considered to decrease because of the displacement of the wall by the coking pressure from an adjacent chamber, and as a result, the resistance to the coke pushing effort increases. $^{6,7)}$

Most of the coke ovens now in operation in Japan were constructed in the 1960 s to 1970 s, thus they have been in operation for as long as 30 to 40 years. The structural strength of the walls of coke oven chambers decreases during long years of operation because of the decrease in the bracing force from buckstays, the expansion of the oven structure in the chamber-length direction, damage to the bricks, and so forth, ${ }^{8)}$ and therefore, the effects of the coking pressure on the oven structure and the coke pushing effort are more significant with an old oven battery than with a new one.

In view of the above, the authors measured the displacement of chamber walls continuously during the operation of a commercially operating coke oven battery, and studied, in consideration of the oven age, the relationship between the wall displacement due to coking pressure and the ease of coke pushing. This paper reports the results.

\section{Experimental Procedure}

\subsection{Coking Chambers Used for Testing}

The subject coking chambers of the measurement of wall displacement were the No. 46 and 72 chambers of the Hokkai No. 6 coke oven battery of Hokkai Iron and Coke Corporation, with 40 coking chambers from No. 43 to 82 , each $6.5 \mathrm{~m}$ in height, $0.43 \mathrm{~m}$ in average width, and $14.8 \mathrm{~m}$ in effective length. The battery entered into operation in 1979, and thus was 26.3 years old at the time of measurement. It has to be noted, however, that all the bricks of the soles to the oven tops of the No. 43 to 47 chambers at the end of the battery were replaced with new ones after 25.3 years of operation. This means that, while one of the subject chambers, No. 72, was more than 26 years old (an old chamber), the other, No. 46, was only 1 year old (a sturdy chamber) at the time of measurement.

\subsection{Measuring Wall Displacement}

Figure 1 schematically shows the equipment used for the measurement of wall displacement. The probe was fabricated by bending a carbon steel pipe for pressure service (JIS STPG), $34 \mathrm{~mm}$ in outer diameter and $3.4 \mathrm{~mm}$ in wall thickness, into a "U" shape and welding flat bars at various 

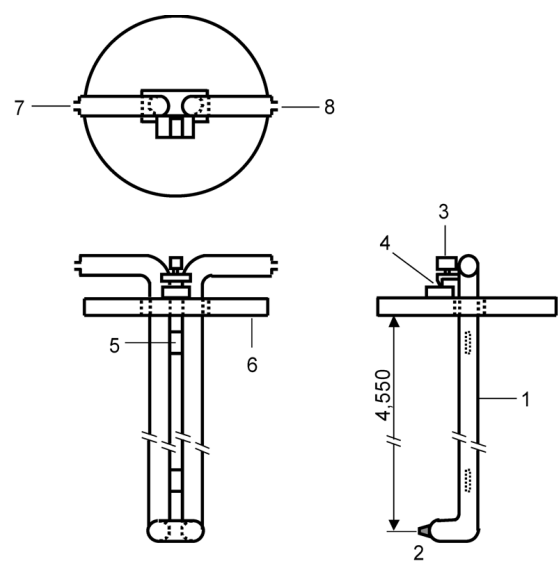

1: probe 2: contact point $\quad 3$ : laser oscillator $\quad 4$ : pivot

5: flat bar 6: temporary lid 7 : water inlet $\quad 8$ : water outlet

Fig. 1. Determination probe for wall displacement.

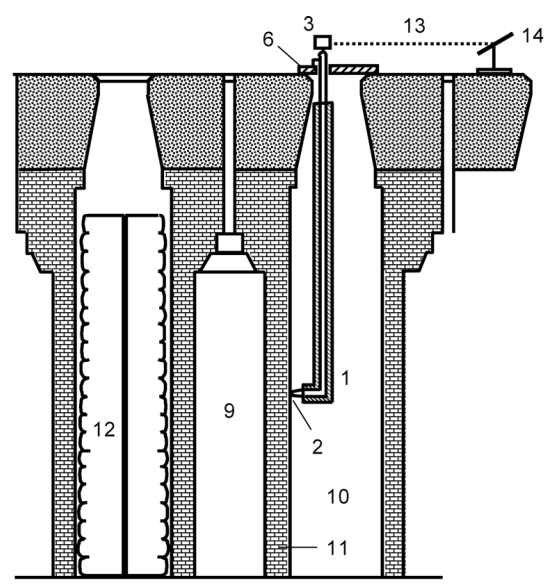

1: probe 2 : contact point 3 : laser oscillator 6 : temporary lid 9: heating flue 10: oven chamber 11: oven wall

12: coke cake 13: laser beam 14: screen

Fig. 2. Side view showing determining wall displacement.

points along the length for reinforcement. A ceramic piece contacting the wall surface was provided at the lower end of the probe. To mitigate the effects of the heat from the wall surfaces, the probe was wrapped with heat-insulating material $25 \mathrm{~mm}$ in thickness, and cooling water was pumped through the pipes at a flow rate of 30 to $40 \mathrm{~L} / \mathrm{min}$.

Figure 2 shows how the probe was set in the coking chamber. A water-cooled temporary lid, $600 \mathrm{~mm}$ in diameter and $16 \mathrm{~mm}$ in thickness, made of JIS SUS304 stainless steel and having a hole for the probe, was set at a charging hole. The probe, supported on a pivot on the lid, hung down into the chamber through the hole of the lid so that the ceramic piece contacted the wall surface. When the position of the contact piece changes because of wall displacement, the probe tilts in the chamber width direction about the pivot, and the amount of tilting is determined by reading, on beam-receiving screen 14, the position change of the bright spot of a laser beam irradiated from oscillator 3 mounted on the probe's top.

Figure 3 shows the principle of determining the wall displacement from the position change of the bright spot on the screen. The wall displacement $L_{1}$ is calculated from the probe length $L_{3}$ and its tilting angle $\alpha$ using the following equation:

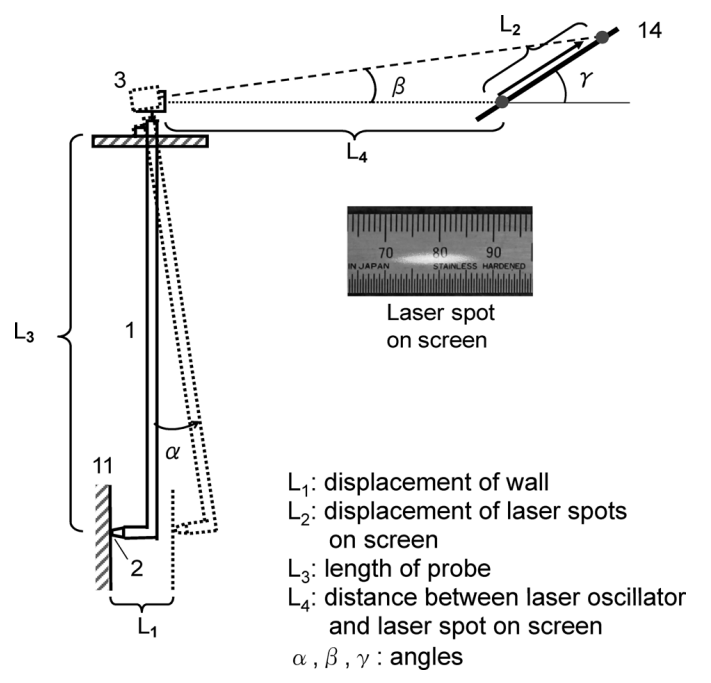

Fig. 3. Schematic representation of determining wall displacement.

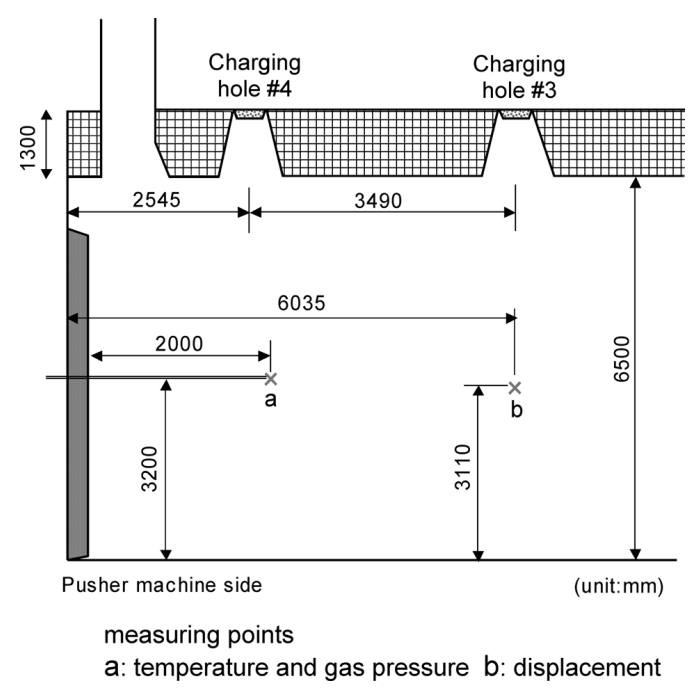

Fig. 4. Measuring points of gas pressure, temperature and wall displacement.

$$
L_{1}=L_{3} \cdot \sin (\alpha)
$$

Here, the tilting angle $\alpha$ of the probe, which is equal to the tilting angle $\beta$ of the laser beam, is calculated using the following equation:

$$
\alpha=\beta=\tan ^{-1}\left(L_{2} \cdot \sin (\gamma) /\left(L_{4}+L_{2} \cdot \cos (\gamma)\right)\right)
$$

where, $\gamma$ is the tilting angle of the screen, $L_{2}$ is the position change of the bright spot on the screen, and $L_{4}$ is the distance from the laser oscillator to the default position of the bright spot. Because the values of $L_{4}$ and $\gamma$ were known, the wall displacement $L_{1}$ could be calculated from the reading of $L_{2}$. The position of the bright spot on the screen was measured at intervals of 15 to $30 \mathrm{~min}$.

Figure 4 shows the measurement position of the wall displacement. The probe entered the chamber through the No. 3 charging hole so that the contact piece touched the wall surface at a point $3.11 \mathrm{~m}$ above the sole and $6.04 \mathrm{~m}$ from the pusher-side end. This point coincided with the position of binder bricks between combustion flues behind the wall, and the wall displacement of a coking chamber into 
Table 1. Experimental conditions.

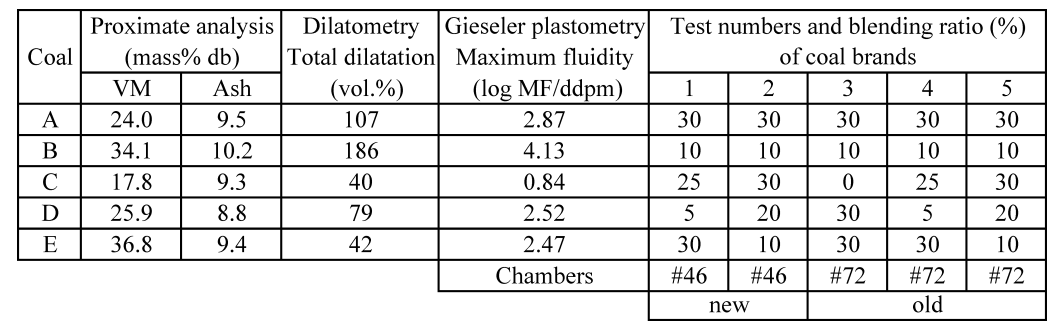

which coal is charged is transmitted to an adjacent chamber through binder bricks.

When a coal-charging car (a larry car) passes over the subject chamber of the measurement, its weight causes the strain of the chamber walls, and for this reason, the car coming over the subject chamber and five adjacent chambers on either side (11 chambers in total) was limited to the least inevitable during the period from coal charging into the chamber in question to the time when the coking pressure subsided.

\subsection{Measuring Gas Pressure and Temperature of Coal Charge}

In parallel to the measurement of wall displacement, the gas pressure of the coal charge and the coal temperature were also measured during the coking process. The gas pressure was measured at a width-center position $3.2 \mathrm{~m}$ above the sole and $2.0 \mathrm{~m}$ from the brick lining of the pusher-side door, using stainless steel tubes (JIS SUS304), $1 \mathrm{~mm}$ in inner diameter and $2 \mathrm{~mm}$ in outer diameter, inserted through the brick lining of the door, as illustrated in Fig. 4. Because the tube might become clogged with fine coal during insertion, three pipes were inserted together, and the highest reading of the three at the time of the coalescence of the plastic layers of the coal was adopted as valid.

The coal temperature was measured at the same position of the gas pressure measurement using a type-K sheathed thermocouple.

\subsection{Coke Oven Operation and Measurement Condi- tions}

Table 1 shows the coal blends (expressed as test numbers 1 to 5) used as the oven charges for measurement, which took place over a period of one week in February 2005. The oven temperature during the period was $1160^{\circ} \mathrm{C}$, the coking time 17.1 to $17.6 \mathrm{~h}$, and the soaking time 2.7 to $3.7 \mathrm{~h}$. To raise the gas pressure up to 8 to $10 \mathrm{kPa}$, a pressure range considered critical to the integrity of chamber walls, the blending ratio of a high-coking-pressure brand of coal ( $\mathrm{C}$ in Table 1) was raised to $30 \%$ at the highest, only for test purposes. Two coal blends (test numbers 1 and 2) were used for the No. 46 chamber (a sturdy chamber), and three others (test numbers 3, 4 and 5) for No. 72 (an old chamber), and the wall displacement was measured by installing the probes in the adjacent chambers, No. 45 and 71, respectively, which were left idle without coal charges. In addition, the flow of the combustion gas was controlled to keep the temperature of the idle chambers within an adequate range.

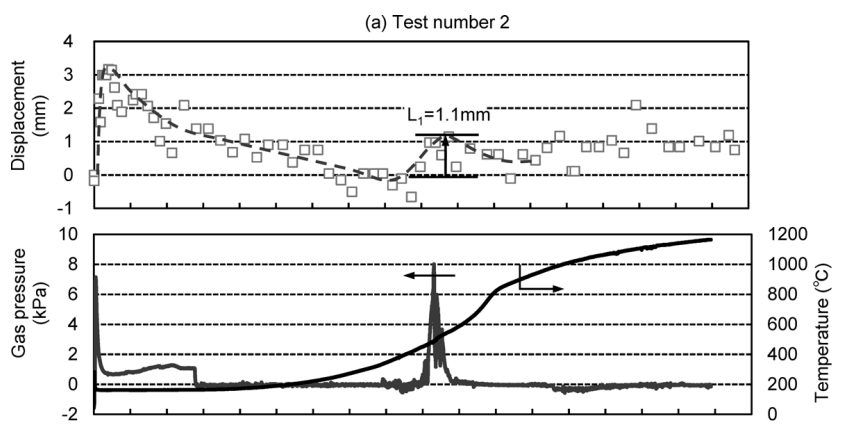

(b) Test number 3

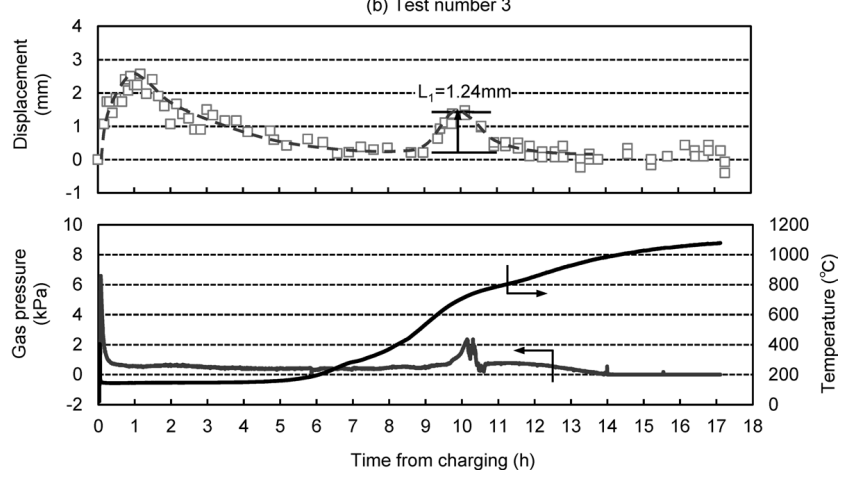

Fig. 5. Profiles of gas pressure, temperature and wall displacement after charging coal of test numbers 2 (part a) and 3 (part b).

\section{Results and Discussion}

As examples of the measurement results, Part (a) of Fig. 5 shows the measurement results obtained with the No. 46 chamber (a sturdy chamber) using the coal blend of test number 2, and Part (b) the same obtained with the No. 72 chamber (an old chamber) using the coal blend of test number 3. Here, a positive wall displacement refers to that toward the width center of the idle chamber.

Figure 5 shows that, with both the sturdy and old chambers, the walls deformed significantly to a maximum of about $3 \mathrm{~mm}$ shortly after coal charging, the displacement decreased gradually thereafter, and then the wall displacement increased again about 9 to $10 \mathrm{~h}$ after charging, to hit a maximum. Because the latter displacement peak was observed exactly when the temperature reached to the softening temperature of the coal and the maximum internal gas pressure occurred at the oven center, the authors consider that it is due to the coking pressure of the coal.

In the case of test number 2, shown in Part (a), wall displacement was detected several times even after $10 \mathrm{~h}$, when the coking pressure of coal had subsided. This is presumably due to the travelling of the larry car over the chamber.

Rueckel $^{9,10)}$ and Ishikawa et al. $^{11)}$ have reported significant displacement of chamber walls immediately after coal 
charging. Possible causes of this kind of wall displacement include thermal stress on the surface layers of chamber-wall bricks, due to rapid cooling, powder pressure of charged coal, and gas pressure at an early stage of coking. However, in consideration of the fact that the wall displacement was largest when the gas pressure was falling after hitting the initial peak, as seen with Fig. 5, the authors consider that the initial wall displacement is mainly due to thermal stress.

Figure 6 shows the relationship between the highest gas pressure of the coal in a coking cycle and wall displacement. Wall displacement increased roughly in proportion to the maximum gas pressure. The ratio of wall displacement to maximum gas pressure $(\mathrm{mm} / \mathrm{kPa})$ calculated from the gradient of the plotting for the old chamber was nearly five times that for the sturdy chamber. This is presumably because the walls of the old chamber have a larger number of wider vertical cracks, ${ }^{13)}$ and for this reason, is less resistant to deformation by the coking pressure.

Table 2 and Fig. 7 show the results of the present meas-

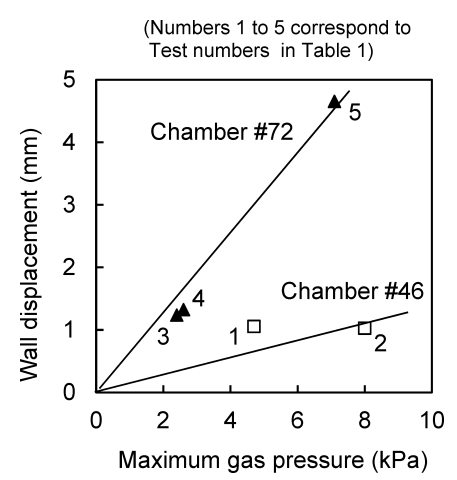

Fig. 6. Relationship between maximum gas pressure and wall displacement. urement in comparison with what different papers reported in the past. The ratio of wall displacement to maximum gas pressure of the old chamber (No. 72) of the Hokkai No. 6 battery $(0.68 \mathrm{~mm} / \mathrm{kPa})$ was nearly twice that of the Dunkerque B6 battery $(0.37 \mathrm{~mm} / \mathrm{kPa})$, of the same chamber height. While wall displacement naturally varied depending on the chamber height and the age and type of oven, considering the operating years of the two batteries at the time of measurement (26 years for the Hokkai No. 6 versus 15 years for Dunkerque B6), these results are reasonably consistent with each other.

Figure 8 shows the relationship between oven age and wall displacement. The ratio of wall displacement to the maximum gas pressure tends to increase with oven age. Coke ovens are known to expand in the chamber-length direction with increasing age, ${ }^{14)}$ and it has also been made clear that vertical cracks develop in chamber walls of an old oven at more or less regular intervals in the chamber length direction. ${ }^{13)}$ Because these cracks are considered to become wider with oven age, the results shown in Fig. 8 indicate that the resistance of chamber walls to lateral force decreases with age as the cracks become wider. The reason why the ratio of wall displacement to maximum gas pressure of the Drocourt No. 11 battery is very low for its age is presumably because its chamber height is low, and consequently, the walls are sturdier than those of taller chambers. $^{12)}$

Now that it became clear that coking chamber walls deform under the pressure of gas generated from coal (coking pressure), the authors took up examining the effects of wall displacement on the resistance to the coke pushing effort. Here, the authors did not measure the wall displacement itself, but examined the relationship between the maximum coking pressure during a coking cycle and the maximum

Table 2. Present and previous studies on wall displacement by coking pressure.

\begin{tabular}{|l|c|c|c|c|c|c|c|c|}
\cline { 3 - 8 } \multicolumn{1}{c|}{} & \multirow{2}{*}{$\begin{array}{c}\text { Years } \\
\text { from }\end{array}$} & $\begin{array}{c}\text { Maximum gas } \\
\text { pressure }(\mathrm{a})\end{array}$ & $\begin{array}{c}\text { Wall dis- } \\
\text { placement }(\mathrm{b})\end{array}$ & \multirow{2}{*}{$(\mathrm{b}) /(\mathrm{a})$} & \multicolumn{3}{|c|}{ Dimension of chamber } & \\
\cline { 5 - 8 } & start & $(\mathrm{kPa})$ & $(\mathrm{mm})$ & $(\mathrm{mm} / \mathrm{kPa})$ & \multicolumn{3}{|c|}{$(\mathrm{m})$} & \\
\hline Hokkai No.6, \#46 & 1 & 8.0 & 1.1 & 0.14 & 6.5 & 0.43 & 15.8 & Present \\
Hokkai No.6, \#72 & 26 & 7.1 & 4.8 & 0.68 & 6.5 & 0.43 & 15.8 & work \\
\hline Dunkerque B6 & 15 & 13.3 & 1 & 0.08 & 6.5 & 0.46 & 15.7 & \\
Dunkerque B6 & 15 & 4.1 & 1.5 & 0.37 & 6.5 & 0.46 & 15.7 & \multirow{2}{*}{$9)$} \\
Drocourt \#11 & 50 & 67 & 2 & 0.03 & 4.25 & 0.50 & 12.4 & \\
\hline BCRA & 21 & 31.7 & 9.7 & 0.31 & 3.8 & 0.457 & 12.4 & $2)$ \\
\hline Bergbau-Forschung & - & 29.4 & 14 & 0.48 & 4.2 & - & 12.7 & \multirow{2}{*}{$3)$} \\
test oven & - & 47.0 & 55 & 1.17 & 4.2 & - & 12.7 & \\
\hline
\end{tabular}

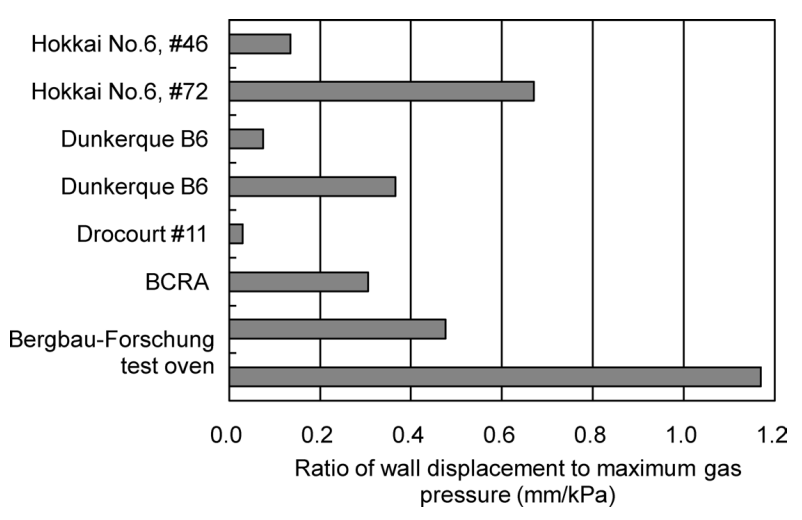

Fig. 7. Comparison of present and previous results on wall displacement.

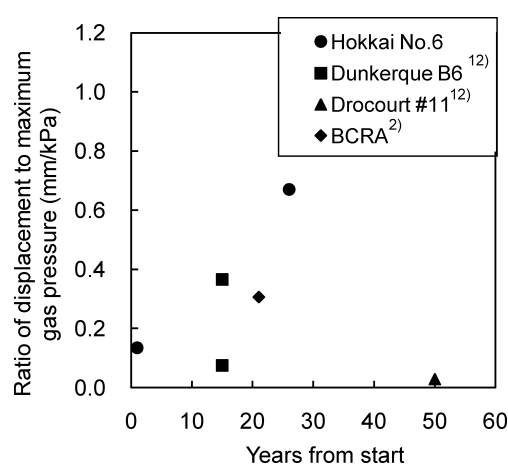

Fig. 8. Relationship between oven age and wall displacement. 
current (amperage) of the drive motor of the pusher, which corresponds to the resistance to the coke pushing effort. Figure 9 shows the results. Whereas the amperage increased significantly as the maximum gas pressure increased in the case of the old chamber susceptible to wall displacement, the effects of gas pressure on the amperage were small in the case of the sturdy one.

The authors surmise the reasons for the above difference in the coke pushing force between the sturdy and old chambers, as illustrated in Fig. 10. When a coke-oven battery is new and chamber walls are resistant to deformation, wall displacement $\mathrm{Db}$ due to coking pressure is small, and therefore, the gap Gp between a chamber wall and the coke cake, which results from the lateral shrinkage Ls of coke after the coking pressure has subsided, remains substantially unchanged $\left.(\mathrm{Gp} \approx \mathrm{Ls}) .{ }^{6}\right)$ In contrast, when a coke-oven battery is old and chamber walls are susceptible to deformation, the wall/coke gap decreases by the sum of the wall displacement $\mathrm{Db}$ due to the coking pressure of the chamber in question and the wall displacement Dc due to the coking pressure of an adjacent chamber $(\mathrm{Gp}=\mathrm{Ls}-\mathrm{Db}-\mathrm{Dc})$. Although the resistance to coke pushing effort changes depending on various factors, the wall/coke gap is considered to have the most significant influence over it - the smaller the gap, the

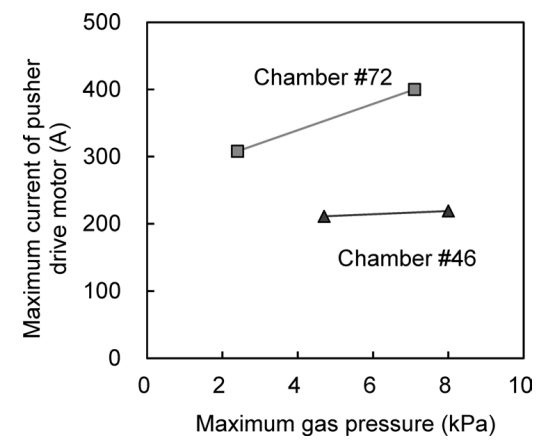

Fig. 9. Relationship between maximum gas pressure and coke pushing amperage. larger the resistance becomes, and consequently, so does the maximum amperage of the drive motor of the pusher. ${ }^{6,7,15)}$ The above indicates that the effects of coking pressure on the resistance to the coke pushing effort are more significant with old coke ovens that are susceptible to wall deformation.

It has to be noted that, with a commercially operating coke-oven battery, as far as normal oven operation is concerned, the coke-pushing operation out of a chamber while the coking pressure in an adjacent chamber is high is unlikely. With an old battery, however, operation cycles of coking chambers are sometimes disturbed, and the cokepushing operation of a chamber may be adversely affected by wall displacement unless careful attention is paid to the coking stages of adjacent chambers.

\section{Conclusions}

Using coking chambers after 26 years of operation (an old chamber) and after 1 year of a total change of bricks from the chamber sole to the oven top (a sturdy chamber) of the same coke oven battery, the authors examined the effects of the gas pressure of the plastic layer of coal in a coking chamber (coking pressure) over chamber wall displacement and consequent resistance to the coke pushing effort at coke discharging, and obtained the following findings:

(1) The chamber walls of both the old and sturdy chambers deformed during the period when the plastic layers met at the oven center and the gas pressure of the coal was highest.

(2) While the wall displacement changed in proportion to the coal gas pressure, the ratio of the displacement to the maximum gas pressure in a coking cycle was larger with the old chamber than with the sturdy ones.

(3) The effects of the gas pressure on the resistance to the coke pushing effort were small with a sturdy chamber. In contrast, with an old chamber, the resistance to the coke pushing effort changed significantly depending on gas pres-

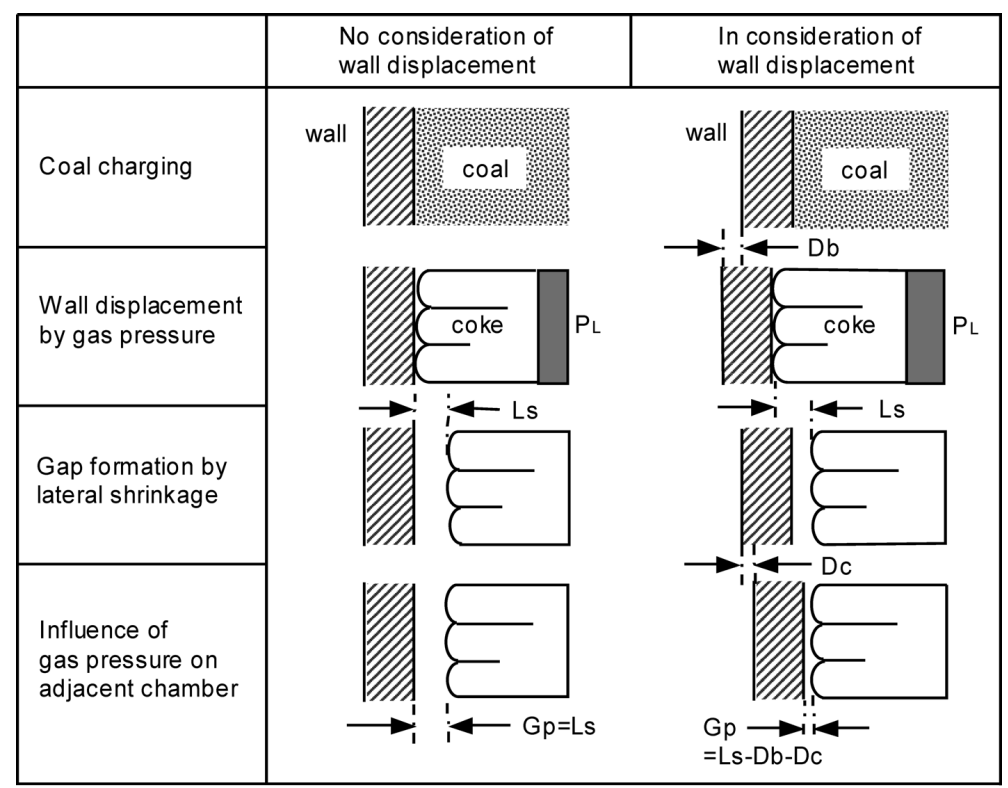

Db, Dc: Wall displacement, Gp: Gap between wall and coke cake

Ls: Lateral shrinkage, PL: Plastic layer

Fig. 10. Influence of wall displacement and lateral shrinkage of coke on gap between wall and coke cake. 
sure, presumably because chamber walls deform more easily under the coking pressure of an adjacent chamber.

\section{REFERENCES}

1) H. Koppers and A. Jenkner: Fuel, 10 (1931), 232.

2) J. L. Lambert, W. J. Lancucki-Pater and G. W. Lee: J. Inst. Fuel, 30 (1957), 362.

3) W. Rohde, D. Hbermehl and V. Kolitz: Ironmaking Conf. Proc., Vol. 47, ISS, Warrendale, (1988), 135.

4) M.te Lindert and J. Tilma: Ironmaking Conf. Proc., Vol. 46, ISS, Warrendale, (1987), 313.

5) J. Tucker and G. Everitt: Ironmaking Conf. Prec., Vol. 48, ISS, Warrendale, (1989), 599.

6) S. Nomura and T. Arima: Tetsu-to-Hagané, 85 (1999), 289.

7) T. Arima, K. Fukuda and K. Kato: Tetsu-to-Hagané, 90 (2004), 728.
8) K. Masamori, Y. Ito and Y. Nakagawa: Ironmaking Conf. Proc., Vol. 57, ISS, Warrendale, (1998), 1143.

9) R. L. Rueckl: Ironmaking Conf. Proc., Vol. 46, ISS, Warrendale, (1987), 269.

10) R. L. Rueckl: Ironmaking Conf. Proc., Vol. 48, ISS, Warrendale, (1989), 619.

11) S. Ishikawa, M. Uchida, T. Honda and C. Uematsu: CAMP-ISIJ, 22 (2009), 154.

12) E. Petit, J. P. Gaillet, J. L. Karst and N. Bastian: Rev. Met. ATS, JSI, Paris, (2002), 88.

13) M. Sakaida, M. Yokomizo, T. Kajiya, M. Sugiura and Y. Nakashima: Ironmaking Conf. Proc., Vol. 61, ISS, Warrendale, (2002), 363.

14) I. Komaki, T. Matsuo, Y. Kogushi, K. Nishimoto and H. Yamamoto: Ironmaking Conf. Proc., Vol. 44, ISS, Warrendale, (1985), 595.

15) V. I. Ades and D. R. Barzan: Ironmaking Conf. Proc., Vol. 45, ISS, Warrendale, (1986), 459. 